\title{
Subtilisin-Catalyzed Resolution of $\mathbf{N}$-Acyl Arylsulfinamides
}

Christopher K. Savile ${ }^{\dagger}$, Vladimir P. Magloire and Romas J. Kazlauskas*, ${ }^{\dagger}$

Department of Chemistry, McGill University, 801 Sherbrooke Street West, Montréal, Québec, Canada, H3A 2K6

${ }^{\dagger}$ Current Address: Department of Biochemistry, Molecular Biology \& Biophysics and the Biotechnology Institute, University of Minnesota, 1479 Gortner Avenue, Saint Paul, MN 55108 USA

*Correspondence to: R. J. Kazlauskas, Department of Biochemistry, Molecular Biology \& Biophysics and the Biotechnology Institute, University of Minnesota, 1479 Gortner Avenue, Saint Paul, MN 55108 USA. Tel +1 (612) 624-5904; Fax +1 (612) 625-5780 E-mail: rjk@umn.edu

\section{Supporting Information}

Synthesis of Racemic Sulfinamides. Racemic sulfinamides were prepared using literature procedures. ${ }^{1}$ Analytical data are given below.

p-Toluenesulfinamide (1). Obtained as white crystals (6.51 g, 56\% overall yield): $\mathrm{mp}$ 115-117 ${ }^{\circ} \mathrm{C}$ (lit. $\left.{ }^{1} 117-118{ }^{\circ} \mathrm{C}\right) ;{ }^{1} \mathrm{H}$ NMR $\delta 2.42$ (s, 3H, PhCH $\left.H_{3}\right), 4.30$ (br s, $\left.2 \mathrm{H},-\mathrm{NH}_{2}\right), 7.30$ (d, $J$ $=8.1,2 \mathrm{H}$, phenyl), $7.62(\mathrm{~d}, J=8.1,2 \mathrm{H}$, phenyl $) ;{ }^{13} \mathrm{C}$ NMR $\delta 21.7\left(\mathrm{PhCH}_{3}\right), 125.6,129.7,141.5$, 143.6 (phenyl). The enantiomers were separated by HPLC (Diacel OD column, 90:10 hexanes/EtOH, $\left.0.5 \mathrm{~mL} / \mathrm{min}, 238 \mathrm{~nm} ;(R)-\mathbf{1}, t_{\mathrm{R}}=21.0 \mathrm{~min} ;(S)-\mathbf{1}, t_{\mathrm{R}}=27.5 \mathrm{~min}\right)$.

Benzenesulfinamide (2). Obtained as white crystals (3.06 g, 59\% overall yield): mp 104$106{ }^{\circ} \mathrm{C} ;{ }^{1} \mathrm{H}$ NMR $\delta 4.38$ (br s, $2 \mathrm{H}, \mathrm{NH}$ ), 7.51 (m, 3H, phenyl), 7.75 (m, 2H, phenyl); ${ }^{13} \mathrm{C}$ NMR (101 MHz) $\delta 125.6,129.1,131.3,146.6$ (phenyl). The enantiomers were separated by HPLC 
(Diacel OD column, 90:10 hexanes/EtOH, $0.5 \mathrm{~mL} / \mathrm{min}, 238 \mathrm{~nm} ;(R)-\mathbf{2}, t_{\mathrm{R}}=22.6 \mathrm{~min} ;(S)-\mathbf{2}, t_{\mathrm{R}}=$ $26.2 \mathrm{~min})$.

p-Chlorobenzenesulfinamide (3). Obtained as amber crystals (9.91 g, 53\% overall yield): mp 130-132 ${ }^{\circ} \mathrm{C} ;{ }^{1} \mathrm{H}$ NMR (DMSO-d 6 ) $\delta 4.39\left(\mathrm{br} \mathrm{s}, 2 \mathrm{H}, \mathrm{N} H_{2}\right.$ ), $7.48(\mathrm{~d}, J=8.7,2 \mathrm{H}$, phenyl), 7.68 (d, $J=9.0,2 \mathrm{H}$, phenyl); ${ }^{13} \mathrm{C}$ NMR $(101 \mathrm{MHz}) \delta 127.3,129.4,137.8,145.1$ (phenyl). The enantiomers were separated by HPLC (Diacel OD column, 90:10 hexanes/EtOH, $\left.0.5 \mathrm{~mL} / \mathrm{min}, 238 \mathrm{~nm} ;(R)-3, t_{\mathrm{R}}=24.7 \mathrm{~min} ;(S)-3, t_{\mathrm{R}}=43.0 \mathrm{~min}\right)$.

p-Methoxybenzenesulfinamide (4). Obtained as white crystals (2.90 g, $35 \%$ overall yield): mp 129-131 ${ }^{\circ} \mathrm{C}$ (lit. ${ }^{2} 135-136$ ); ${ }^{1} \mathrm{H}$ NMR $\delta 3.86$ (s, $3 \mathrm{H},-\mathrm{OCH} H_{3}$ ), 4.29 (br s, $2 \mathrm{H}, \mathrm{NH} H_{2}$ ), 7.00 (d, $J=9.0,2 \mathrm{H}$, phenyl), 7.66 (d, $J=9.0,2 \mathrm{H}$. phenyl); ${ }^{13} \mathrm{C}$ NMR (DMSO-d $)$ ) $56.2\left(-\mathrm{OCH}_{3}\right)$, 114.7, 127.7, 140.2, 161.4 (phenyl). The enantiomers were separated by HPLC (Diacel OD column, 90:10 hexanes/EtOH, $\left.0.5 \mathrm{~mL} / \mathrm{min}, 238 \mathrm{~nm} ;(R)-\mathbf{4}, t_{\mathrm{R}}=28.8 \mathrm{~min} ;(S)-\mathbf{4}, t_{\mathrm{R}}=41.4 \mathrm{~min}\right)$.

2,4,6-Trimethylbenzenesulfinamide (5). Obtained as a white crystals (6.03 g, 33\% overall yield): mp 116-118 ${ }^{\circ} \mathrm{C}$ (lit. ${ }^{2} 115-118{ }^{\circ} \mathrm{C}$ ); ${ }^{1} \mathrm{H}$ NMR $\delta 2.29$ (s, 3H, PhCH $), 2.61$ (s, 6H, 2 x PhCH $\left.H_{3}\right), 4.41$ (br s, 2H, NH $\left.H_{2}\right), 6.86$ (s, 2H, phenyl); ${ }^{13} \mathrm{C} \mathrm{NMR} \mathrm{(DMSO-d} 6$ ) $\delta 19.8\left(2 \mathrm{x} \mathrm{PhCH}_{3}\right)$, $21.3\left(\mathrm{PhCH}_{3}\right), 130.8,136.2,139.8,140.9$ (phenyl). The enantiomers were separated by HPLC (Diacel OD column, 90:10 hexanes/EtOH, $0.5 \mathrm{~mL} / \mathrm{min}, 238 \mathrm{~nm} ;(R)-\mathbf{5}, t_{\mathrm{R}}=26.8 \mathrm{~min} ;(S)-\mathbf{5}, t_{\mathrm{R}}=$ $25.0 \mathrm{~min})$.

1-Naphthylenesulfinamide (6). Obtained as amber crystals ( $2.20 \mathrm{~g}, 55 \%$ overall yield): mp 166-168 ${ }^{\circ} \mathrm{C} ;{ }^{1} \mathrm{H}$ NMR (DMSO-d $\left.\mathrm{d}_{6}\right) \delta 6.26$ (br s, $2 \mathrm{H}, \mathrm{NH} \mathrm{H}_{2}$ ), 7.58-7.70 (m, 3H, phenyl), 8.018.08 (m, 3H. phenyl), 8.18-8.21 (m, 1H, phenyl); ${ }^{13} \mathrm{C}$ NMR (DMSO-d 6 ) $\delta 122.9,123.8,125.8$, $127.0,127.4,129.2,129.3,131.6,133.9,143.8$ (phenyl). The enantiomers were separated by 
HPLC (Diacel OD column, 90:10 hexanes/EtOH, $0.5 \mathrm{~mL} / \mathrm{min}, 238 \mathrm{~nm} ;(R)-6, t_{\mathrm{R}}=32.9 \mathrm{~min} ;(S)$ $\left.\mathbf{6}, t_{\mathrm{R}}=39.5 \mathrm{~min}\right)$

2,4,6-Triisopropylbenzenesulfinamide (7). Obtained as a white solid (2.51 g, 21\% overall yield): $\mathrm{mp}$ (decomp.) $183-185{ }^{\circ} \mathrm{C}$ (lit. $\left.{ }^{1} 99-102{ }^{\circ} \mathrm{C}\right)^{3} ;{ }^{1} \mathrm{H}$ NMR $\delta 1.24(\mathrm{~d}, J=6.9,6 \mathrm{H}, 2 \mathrm{x}$ $\left.\mathrm{CH}_{3}\right), 1.27\left(\mathrm{~d}, J=6.6,6 \mathrm{H}, 2 \times \mathrm{CH}_{3}\right), 1.32\left(\mathrm{~d}, J=7.2,6 \mathrm{H}, 2 \times \mathrm{CH}_{3}\right), 2.88$ (sept, $J=6.6,1 \mathrm{H}$, $\left.\mathrm{CH}\left(\mathrm{CH}_{3}\right)\right), 4.03$ (sept, $\left.J=6.7,2 \mathrm{H}, 2 \times \mathrm{CH}\left(\mathrm{CH}_{3}\right)\right), 4.48$ (br s, $\left.2 \mathrm{H}, \mathrm{N} H_{2}\right) 7.07$ (s, 2H, phenyl); ${ }^{13} \mathrm{C}$ NMR $\left(\right.$ DMSO-d $\left._{6}\right) \delta 24.6,24.7,25.1,25.7,28.7,34.3,(i-P r), 122.5,141.5,147.3,149.5$. The enantiomers were separated by HPLC (Diacel OD column, 90:10 hexanes/EtOH, $0.5 \mathrm{~mL} / \mathrm{min}$, $238 \mathrm{~nm} ;(R$ or $S)-7, t_{\mathrm{R}}=8.5 \mathrm{~min} ;(R$ or $\left.S)-7, t_{\mathrm{R}}=10.5 \mathrm{~min}\right)$.

tert-Butylsulfinamide (8). $m$-CPBA (14 g, $62 \mathrm{mmol})$ in $\mathrm{CH}_{2} \mathrm{Cl}_{2}(100 \mathrm{~mL})$ was added dropwise to a stirred solution of tert-butyldisulfide $(10 \mathrm{~g}, 56 \mathrm{mmol})$ in $\mathrm{CH}_{2} \mathrm{Cl}_{2}(25 \mathrm{~mL})$ at $0{ }^{\circ} \mathrm{C}$ over $15 \mathrm{~min}$. The solution was stirred for $30 \mathrm{~min}$ at $0{ }^{\circ} \mathrm{C}$ and $\mathrm{RT}$ until the reaction was complete by TLC $(3 \mathrm{~h})$. The reaction mixture was poured into a separatory funnel containing $\mathrm{CH}_{2} \mathrm{Cl}_{2}(100$ $\mathrm{mL})$ and sat. $\mathrm{NaHCO}_{3}(100 \mathrm{~mL})$ and further extracted with $\mathrm{CH}_{2} \mathrm{Cl}_{2}(2 \times 100 \mathrm{~mL})$. The organic layer was removed and washed with sat. $\mathrm{NaHCO}_{3}(3 \times 100 \mathrm{~mL})$, sat. $\mathrm{NaCl}(100 \mathrm{~mL})$, dried over $\mathrm{Na}_{2} \mathrm{SO}_{4}$ and concentrated in vacuo to give $10.34 \mathrm{~g}(95 \%)$ of tert-butylthiosulfinate ${ }^{4} ;{ }^{1} \mathrm{H} \mathrm{NMR}$ $(200 \mathrm{MHz}) \delta 1.32$ (sulfide) $1.39\left(\mathrm{~s}, 9 \mathrm{H},\left(\mathrm{CH}_{3}\right)_{3} \mathrm{~S}\right), 1.57\left(\mathrm{~s}, 9 \mathrm{H},\left(\mathrm{CH}_{3}\right)_{3} \mathrm{~S}=\mathrm{O}\right)$. This intermediate was dissolved in $\mathrm{CH}_{2} \mathrm{Cl}_{2}(25 \mathrm{~mL})$ and a solution of $\mathrm{SO}_{2} \mathrm{Cl}_{2}(7.2 \mathrm{~g}, 53 \mathrm{mmol})$ in $\mathrm{CH}_{2} \mathrm{Cl}_{2}(10 \mathrm{~mL})$ was added dropwise at $0{ }^{\circ} \mathrm{C}$. The resulting yellow solution was stirred for $1 \mathrm{~h}$ allowing it to gradually reach $\mathrm{RT}^{5}$ Excess $\mathrm{SO}_{2} \mathrm{Cl}_{2}$ was removed under vacuum and the resulting product, tertbutylsufinyl chloride, was diluted in $\mathrm{CH}_{2} \mathrm{Cl}_{2}(100 \mathrm{~mL})$ and added dropwise to $\mathrm{NH}_{4} \mathrm{OH}(200 \mathrm{~mL})$ at $0{ }^{\circ} \mathrm{C}$ over $30 \mathrm{~min}$. After stirring for $30 \mathrm{~min}$ at $\mathrm{RT}$, the reaction mixture was saturated with $\mathrm{NaCl}$ and extracted with $\mathrm{CH}_{2} \mathrm{Cl}_{2}(3 \times 100 \mathrm{~mL})$. The combined organic layers were washed with 
sat. $\mathrm{NaCl}(150 \mathrm{~mL})$, dried over $\mathrm{Na}_{2} \mathrm{SO}_{4}$ and concentrated in vacuo to give the crude sulfinamide. Purification using flash chromatography $\left(12: 1 \mathrm{CHCl}_{3} / \mathrm{MeOH}\right)$ gave the title compound $(1.41 \mathrm{~g}$, $22 \%$ ) as a white solid: $\mathrm{mp} 98-100{ }^{\circ} \mathrm{C}$ (lit. ${ }^{6} 101-102{ }^{\circ} \mathrm{C}$ (R-enantiomer) $) ;{ }^{1} \mathrm{H}$ NMR $(200 \mathrm{MHz}) \delta$ $1.23\left(\mathrm{~s}, 9 \mathrm{H},-\left(\mathrm{CH}_{3}\right)_{3}\right), 3.72\left(\right.$ br s, $\left.2 \mathrm{H}, \mathrm{NH} \mathrm{H}_{2}\right) ;{ }^{13} \mathrm{C} \mathrm{NMR} \delta 22.6\left(-\left(\mathrm{CH}_{3}\right)_{3}\right), 55.4\left(\mathrm{C}\left(\mathrm{CH}_{3}\right)_{3}\right)$. The enantiomers were separated by HPLC (Diacel OD column, 90:10 hexanes/EtOH, $0.5 \mathrm{~mL} / \mathrm{min}$, $\left.222 \mathrm{~nm} ;(R)-8, t_{\mathrm{R}}=12.6 \mathrm{~min} ;(S)-8, t_{\mathrm{R}}=15.2 \mathrm{~min}\right)$.

$\mathrm{N}$-Acylsulfinamides. $\mathrm{N}$-Acylsulfinamides of 1-8 were prepared by treating sulfinamides 1-8 with two equivalents of $n$-BuLi in $\mathrm{THF}^{1}$, followed by rapid addition of the symmetrical anhydride of the appropriate carboxylic acid. ${ }^{7}$ The relevant analytical data are given below:

N-Acetyl-p-toluenesulfinamide (1a). Obtained as white solid (95 mg, 30\%): mp 125 $127{ }^{\circ} \mathrm{C} ;{ }^{1} \mathrm{H}$ NMR $\delta 2.21$ (s, 3H, C(O)CH3), 2.45 (s, 3H, PhCH $), 7.35$ (d, J=8.4, 2H, phenyl), $7.59\left(\mathrm{~d}, J=8.1,2 \mathrm{H}\right.$, phenyl); ${ }^{13} \mathrm{C} \mathrm{NMR} \delta 21.8\left(\mathrm{C}(\mathrm{O}) \mathrm{CH}_{3}\right), 21.9\left(\mathrm{PhCH}_{3}\right), 124.9,130.3,140.3$, 142.9 (phenyl), $171.3(C=\mathrm{O})$; HRMS calcd for $\mathrm{C}_{9} \mathrm{H}_{12} \mathrm{NO}_{2} \mathrm{~S}\left(\mathrm{M}+\mathrm{H}^{+}\right)$198.0589. Found: 198.0582. The enantiomers were separated by HPLC (Diacel OD column, 90:10 hexanes/EtOH, 0.5 $\mathrm{mL} / \mathrm{min}, 238 \mathrm{~nm} ;(R$ or $S)-\mathbf{1 a}, t_{\mathrm{R}}=24.6 \mathrm{~min} ;(R$ or $\left.S)-\mathbf{1 a}, t_{\mathrm{R}}=36.6 \mathrm{~min}\right)$.

N-Butanoyl-p-toluenesulfinamide (1b). Obtained as white solid (780 mg, 90\%): $\mathrm{mp} 95$ $97{ }^{\circ} \mathrm{C} ;{ }^{1} \mathrm{H} \mathrm{NMR} \delta 1.0\left(\mathrm{t}, J=7.0,3 \mathrm{H},-\mathrm{CH}_{2} \mathrm{CH}_{3}\right), 1.72\left(\mathrm{~m}, 2 \mathrm{H},-\mathrm{CH}_{2} \mathrm{CH}_{3}\right), 2.20(\mathrm{~m}, 2 \mathrm{H}$, $\left.\mathrm{C}(\mathrm{O}) \mathrm{CH}_{2}\right), 2.43\left(\mathrm{~s}, 3 \mathrm{H}, \mathrm{PhCH}_{3}\right), 7.32\left(\mathrm{~d}, J=8,2 \mathrm{H}\right.$, phenyl), $7.57\left(\mathrm{~d}, J=8,2 \mathrm{H}\right.$, phenyl); ${ }^{13} \mathrm{C}$ NMR $\delta 13.9\left(-\mathrm{CH}_{2} \mathrm{CH}_{3}\right), 18.7\left(-\mathrm{CH}_{2} \mathrm{CH}_{3}\right), 21.8\left(\mathrm{PhCH}_{3}\right), 37.2\left(\mathrm{C}(\mathrm{O}) \mathrm{CH}_{2}\right), 124.9,130.1,139.9$, 142.5 (phenyl), $174.7(C=\mathrm{O})$; HRMS calcd for $\mathrm{C}_{11} \mathrm{H}_{16} \mathrm{NO}_{2} \mathrm{~S}\left(\mathrm{M}+\mathrm{H}^{+}\right)$226.0902. Found: 226.0897. The enantiomers were separated by HPLC (Diacel Chiracel OD column, 90:10 hexanes/EtOH, $0.5 \mathrm{~mL} / \mathrm{min}, 238 \mathrm{~nm} ;(R$ or $S)-\mathbf{1 b}, t_{\mathrm{R}}=12.9 \mathrm{~min} ;(R$ or $\left.S)-\mathbf{1 b}, t_{\mathrm{R}}=17.4 \mathrm{~min}\right)$. 
$\boldsymbol{N}$-Bromoacetyl-p-toluenesulfinamide (1d). Obtained as white solid (175 mg, 20\%): mp 83-85 ${ }^{\circ} \mathrm{C} ;{ }^{1} \mathrm{H}$ NMR $\delta 2.46$ (s, 3H, $\left.\mathrm{PhCH}_{3}\right), 3.94$ (s, 2H, C(O)CH $\left.\mathrm{CH}_{2} \mathrm{Br}\right), 7.37$ (d, $J=8.1,2 \mathrm{H}$, phenyl), 7.62 (d, $J=8.1,2 \mathrm{H}$, phenyl); ${ }^{13} \mathrm{C}$ NMR $\delta 21.8\left(\mathrm{PhCH}_{3}\right), 29.6\left(\mathrm{C}(\mathrm{O}) \mathrm{CH}_{2} \mathrm{Br}\right), 125.5$, 130.4, 140.7, 142.6 (phenyl), $168.4(C=\mathrm{O})$; HRMS calcd for $\mathrm{C}_{9} \mathrm{H}_{11}{ }^{79} \mathrm{BrNO}_{2} \mathrm{~S}\left(\mathrm{M}+\mathrm{H}^{+}\right)$275.9694. Found: 275.9698. The enantiomers were separated HPLC (Diacel Chiralcel OD column, 90:10 hexanes/EtOH, $\left.0.5 \mathrm{~mL} / \mathrm{min}, 238 \mathrm{~nm} ;(R)-\mathbf{1 d}, t_{\mathrm{R}}=19.8 \mathrm{~min} ;(S)-\mathbf{1 d}, t_{\mathrm{R}}=48.9 \mathrm{~min}\right)$.

N-Methoxyacetyl-p-toluenesulfinamide (1e). Obtained as white solid (304 mg, 42\%): mp 57-59 ${ }^{\circ} \mathrm{C} ;{ }^{1} \mathrm{H}$ NMR $\delta 2.42$ (s, 3H, $\left.\mathrm{PhCH}_{3}\right), 3.37$ (s, 3H, OCH $), 4.00$ (s, 2H, C(O)CH $), 7.37$ $\left(\mathrm{d}, J=8.4,2 \mathrm{H}\right.$, phenyl), $7.63(\mathrm{~d}, J=8.4,2 \mathrm{H}) 8.29($ br s, $1 \mathrm{H}, \mathrm{NH}) ;{ }^{13} \mathrm{C} \mathrm{NMR} \delta 21.9\left(\mathrm{PhCH}_{3}\right)$, 59.6 $\left(\mathrm{OCH}_{3}\right), 71.9\left(\mathrm{C}(\mathrm{O}) \mathrm{CH}_{2}\right), 124.8,130.3,140.4,142.9$ (phenyl), $170.7(C=\mathrm{O})$; HRMS calcd for $\mathrm{C}_{10} \mathrm{H}_{14} \mathrm{NO}_{3} \mathrm{~S}\left(\mathrm{M}+\mathrm{H}^{+}\right)$228.0694. Found: 228.0689. The enantiomers were separated by HPLC (Diacel OD column, 90:10 hexanes/EtOH, $0.5 \mathrm{~mL} / \mathrm{min}, 238 \mathrm{~nm} ;(R)-\mathbf{1 e}, t_{\mathrm{R}}=24.6 \mathrm{~min} ;(S)-1 \mathbf{e}, t_{\mathrm{R}}$ $=31.7 \mathrm{~min})$.

$N$-[N-(tert-Butoxycarbonyl)-glycine]-p-toluenesulfinamide (1f). Obtained as white solid (290 mg, 29\%): $\mathrm{mp} 128-130{ }^{\circ} \mathrm{C} ;{ }^{1} \mathrm{H} \mathrm{NMR} \delta 1.39$ (s, 9H, $\left.-\mathrm{C}\left(\mathrm{CH}_{3}\right)_{3}\right), 2.43$ (s, 3H, PhCH$)_{3}$, $3.88\left(\mathrm{~m}, 2 \mathrm{H}, \mathrm{C}(\mathrm{O}) \mathrm{CH}_{2}\right), 5.29$ (br s, $\left.1 \mathrm{H}, \mathrm{NH}\right), 7.32$ (d, $J=7.8,2 \mathrm{H}$, phenyl), 7.57 (d, $J=8.1,2 \mathrm{H}$,

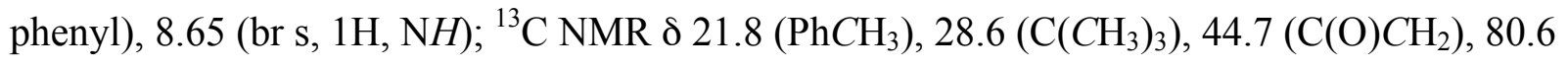
$\left(C\left(\mathrm{CH}_{3}\right)_{3}, 124.9,130.2,139.8,142.7\right.$ (phenyl), $156.4(C=\mathrm{O}$, carbamate), $171.4(C=\mathrm{O}$, amide $)$; HRMS calcd for $\mathrm{C}_{14} \mathrm{H}_{21} \mathrm{~N}_{2} \mathrm{O}_{4} \mathrm{~S}\left(\mathrm{M}+\mathrm{H}^{+}\right)$313.1222. Found: 313.1218 . The enantiomers were separated by HPLC (Diacel OD column, 90:10 hexanes/EtOH, $0.5 \mathrm{~mL} / \mathrm{min}, 238 \mathrm{~nm} ;(R)-\mathbf{1 f}, t_{\mathrm{R}}=$ $\left.17.8 \mathrm{~min} ;(S)-\mathbf{1 f}, t_{\mathrm{R}}=30.9 \mathrm{~min}\right)$.

$N$-[N-(tert-Butoxycarbonyl)-phenylalanine]-p-toluenesulfinamide (1g). Obtained as white solid (660 mg, 51\%): $\mathrm{mp} 111-113{ }^{\circ} \mathrm{C} ;{ }^{1} \mathrm{H}$ NMR $\delta 1.33-1.46\left(\mathrm{~m}, 9 \mathrm{H},\left(\mathrm{CH}_{3}\right)_{3}\right), 2.42(\mathrm{~s}, 3 \mathrm{H}$, 
$\left.\mathrm{PhCH}_{3}\right), 3.11\left(\mathrm{~m}, 2 \mathrm{H}, \mathrm{CH}_{2} \mathrm{Ph}\right), 4.38$ (bs s, 1H, NH), 4.99 (m, 1H, C(O)CH), 7.12-7.53 (m, 9H, phenyl), 8.33 (br s, $1 \mathrm{H}, \mathrm{NH}) ;{ }^{13} \mathrm{C}$ NMR $\delta 21.8\left(\mathrm{PhCH}_{3}\right), 28.6\left(\mathrm{C}\left(\mathrm{CH}_{3}\right)_{3}, 38.7\left(\mathrm{CH}_{2} \mathrm{Ph}\right), 60.8\right.$

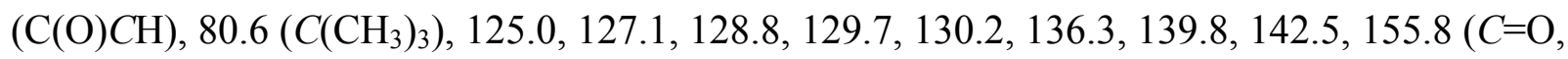
carbamate), $173.2\left(C=\mathrm{O}\right.$, amide); HRMS calcd for $\mathrm{C}_{21} \mathrm{H}_{27} \mathrm{~N}_{2} \mathrm{O}_{4} \mathrm{~S}\left(\mathrm{M}+\mathrm{H}^{+}\right)$403.1691. Found: 403.1683. The enantiomers were separated by HPLC (Diacel OD column, 90:10 hexanes/EtOH, $\left.0.5 \mathrm{~mL} / \mathrm{min}, 238 \mathrm{~nm} ;(S, S)-\mathbf{1 g}, t_{\mathrm{R}}=11.9 \mathrm{~min} ;(R, S)-\mathbf{1 g}, t_{\mathrm{R}}=13.4 \mathrm{~min}\right)$.

$N$-Phenoxyacetyl-p-toluenesulfinamide (1i). Obtained as white solid (391 mg, 42\%): mp 107-109 ${ }^{\circ} \mathrm{C} ;{ }^{1} \mathrm{H}$ NMR $\delta 2.45$ (s, 3H, $\left.\mathrm{PhCH}_{3}\right), 4.60$ (s, 2H, C(O)CH $)$, 6.83-7.06 (m, 3H, phenyl), 7.27-7.36 (m, 4H, phenyl), $7.58(\mathrm{~d}, J=8.1,2 \mathrm{H}) ;{ }^{13} \mathrm{C} \mathrm{NMR} \delta 21.9\left(\mathrm{PhCH}_{3}\right), 67.5$ $\left(C(\mathrm{O}) \mathrm{CH}_{2}\right), 114.9,122.7,124.9,130.0,130.4,140.2,143.1,156.8$ (phenyl), $169.6(\mathrm{C}=\mathrm{O})$; HRMS calcd for $\mathrm{C}_{15} \mathrm{H}_{16} \mathrm{NO}_{3} \mathrm{~S}\left(\mathrm{M}+\mathrm{H}^{+}\right)$290.0851. Found: 290.0843. The enantiomers were separated by HPLC (Diacel OD column, 90:10 hexanes/EtOH, $0.5 \mathrm{~mL} / \mathrm{min}, 238 \mathrm{~nm}$; $(R$ or $S$ )-1i, $t_{\mathrm{R}}=31.4 \mathrm{~min} ;(R$ or $\left.S)-\mathbf{1 i}, t_{\mathrm{R}}=43.8 \mathrm{~min}\right)$.

N-4-Methylvaleroyl-p-toluenesulfinamide (1j). Obtained as white solid (160 mg, 20\%): mp $123-125{ }^{\circ} \mathrm{C} ;{ }^{1} \mathrm{H}$ NMR $\delta 0.90\left(\mathrm{~s}, 3 \mathrm{H}, \mathrm{CH}_{3}\right), 0.93\left(\mathrm{~s}, 3 \mathrm{H}, \mathrm{CH}_{3}\right), 1.56-1.62(\mathrm{~m}, 3 \mathrm{H}$, $\left.\mathrm{CH}_{2} \mathrm{CH}\left(\mathrm{CH}_{3}\right)_{2}\right), 2.40\left(\mathrm{~m}, 2 \mathrm{H}, \mathrm{C}(\mathrm{O}) \mathrm{CH}_{2}\right), 2.45\left(\mathrm{~s}, 3 \mathrm{H}, \mathrm{PhCH}_{3}\right), 7.35$ (d, J=8.6, 2H, phenyl), 7.59 $(\mathrm{d}, J=8.2,2 \mathrm{H}) ;{ }^{13} \mathrm{C} \mathrm{NMR} \delta 21.9\left(\mathrm{PhCH}_{3}\right), 22.6\left(\left(\mathrm{CH}_{3}\right)_{2}\right), 28.0\left(\mathrm{CH}\left(\mathrm{CH}_{3}\right)_{2}\right), 33.9\left(\mathrm{CH}_{2} \mathrm{CH}\right)$ or $\left(\mathrm{C}(\mathrm{O}) \mathrm{CH}_{2}\right), 34.4\left(\mathrm{CH}_{2} \mathrm{CH}\right)$ or $\left(\mathrm{C}(\mathrm{O}) \mathrm{CH}_{2}\right), 124.9,130.1,140.4,142.5$ (phenyl), $174.6(\mathrm{C}=\mathrm{O})$; HRMS calcd for $\mathrm{C}_{13} \mathrm{H}_{20} \mathrm{NO}_{2} \mathrm{~S}\left(\mathrm{M}+\mathrm{H}^{+}\right)$254.1215. Found: 254.1209. The enantiomers were separated by HPLC (Diacel OD column, 90:10 hexanes/EtOH, $0.5 \mathrm{~mL} / \mathrm{min}, 238 \mathrm{~nm} ;(R)-\mathbf{1} \mathbf{j}, t_{\mathrm{R}}=$ $\left.11.9 \min ;(S)-\mathbf{1 j}, t_{\mathrm{R}}=13.7 \mathrm{~min}\right)$.

$\boldsymbol{N}$-Levulinoyl-p-toluenesulfinamide (1k). Obtained as white solid (399 mg, 49\%): mp 74-76 ${ }^{\circ} \mathrm{C} ;{ }^{1} \mathrm{H}$ NMR $\delta 2.20$ (s, 3H, C(O)CH $), 2.44$ (s, 3H, Ph CH$\left.H_{3}\right), 2.61$ (m, 2H, C(O)CH $), 2.86$ 
(m, $\left.2 \mathrm{H}, \mathrm{CH}_{2} \mathrm{C}(\mathrm{O}) \mathrm{CH}_{3}\right), 7.33$ (d, $J=8.6,2 \mathrm{H}$, phenyl), $7.60(\mathrm{~d}, J=8.2,2 \mathrm{H}$, phenyl), 8.08 (br s, 1H, $\mathrm{NH}) ;{ }^{13} \mathrm{C}$ NMR $\delta 21.8\left(\mathrm{PhCH}_{3}\right), 30.1\left(\mathrm{C}(\mathrm{O}) \mathrm{CH}_{3}\right), 30.2\left(\mathrm{C}(\mathrm{O}) \mathrm{CH}_{2}\right), 38.0\left(\mathrm{CH}_{2} \mathrm{C}(\mathrm{O}) \mathrm{CH}_{3}\right)$, 125.0, 130.1, 140.2, 142.5 (phenyl), 173.4 ( $C=\mathrm{O}$, amide), 207.6 ( $C=\mathrm{O}$, ketone); HRMS calcd for $\mathrm{C}_{12} \mathrm{H}_{16} \mathrm{NO}_{3} \mathrm{~S}\left(\mathrm{M}+\mathrm{H}^{+}\right)$254.0851. Found: 254.0857. The enantiomers were separated by HPLC (Diacel OD column, 90:10 hexanes/EtOH, $0.5 \mathrm{~mL} / \mathrm{min}, 238 \mathrm{~nm} ;(R)-\mathbf{1} \mathbf{k}, t_{\mathrm{R}}=30.4 \mathrm{~min} ;(S)-\mathbf{1 k}, t_{\mathrm{R}}$ $=42.9 \mathrm{~min})$.

$N$-Isopropoxyacetyl-p-toluenesulfinamide (11). Obtained as white solid (289 mg, 35\%): $\operatorname{mp} 68-70{ }^{\circ} \mathrm{C} ;{ }^{1} \mathrm{H}$ NMR $(200 \mathrm{MHz}) \delta 1.13\left(\mathrm{t}, J=6.0,3 \mathrm{H}, \mathrm{CH}_{3}\right), 1.23\left(\mathrm{t}, J=5.8,3 \mathrm{H}, \mathrm{CH}_{3}\right), 2.46$ (s, 3H, $\left.\mathrm{PhCH}_{3}\right), 3.63\left(\mathrm{~m}, 1 \mathrm{H}, \mathrm{CH}\left(\mathrm{CH}_{3}\right)_{2}\right), 4.03\left(\mathrm{~s}, 2 \mathrm{H}, \mathrm{C}(\mathrm{O}) \mathrm{CH}_{2}\right), 7.36(\mathrm{~d}, J=7.8,2 \mathrm{H}$, phenyl), $7.64\left(\mathrm{~d}, J=8.2,2 \mathrm{H}\right.$, phenyl) $8.34($ br s, $1 \mathrm{H}, \mathrm{NH}) ;{ }^{13} \mathrm{C} \mathrm{NMR} \delta 21.9\left(\mathrm{PhCH}_{3}\right), 22.1\left(\mathrm{CH}_{3}\right)_{2}, 22.2$ $\left(\mathrm{CH}_{3}\right)_{2}, 67.8\left(\mathrm{CH}\left(\mathrm{CH}_{3}\right)_{2}\right), 124.8,130.3,140.5,142.9$ (phenyl), $171.5(\mathrm{C}=\mathrm{O})$; HRMS calcd for $\mathrm{C}_{12} \mathrm{H}_{18} \mathrm{NO}_{3} \mathrm{~S}\left(\mathrm{M}+\mathrm{H}^{+}\right)$256.1007. Found: 256.1012. The enantiomers were separated by HPLC (Diacel OD column, 90:10 hexanes/EtOH $0.5 \mathrm{~mL} / \mathrm{min}, 238 \mathrm{~nm} ;(R$ or $S)-\mathbf{1 1}, t_{\mathrm{R}}=18.4 \mathrm{~min} ;(R$ or $\left.S)-\mathbf{1 1}, t_{\mathrm{R}}=19.7 \mathrm{~min}\right)$.

N-3-(Methoxycarbonyl)propionyl-p-toluenesulfinamide (1m). Obtained as white solid (561 mg, 65\%): mp 90-92 ${ }^{\circ} \mathrm{C} ;{ }^{1} \mathrm{H}$ NMR $\delta 2.43$ (s, 3H, tolyl $\left.\mathrm{CH}_{3}\right), 2.61\left(\mathrm{~m}, 2 \mathrm{H}, \mathrm{CH}_{2} \mathrm{C}(\mathrm{O}) \mathrm{CH}_{3}\right)$ or $\left(\mathrm{m}, 2 \mathrm{H}, \mathrm{C}(\mathrm{O}) \mathrm{CH}_{2}\right), 2.70\left(\mathrm{~m}, 2 \mathrm{H}, \mathrm{CH}_{2} \mathrm{C}(\mathrm{O}) \mathrm{CH}_{3}\right)$ or $\left(\mathrm{m}, 2 \mathrm{H}, \mathrm{C}(\mathrm{O}) \mathrm{CH}_{2}\right), 7.32(\mathrm{~d}, J=8.4,2 \mathrm{H}$, phenyl), $7.56(\mathrm{~d}, J=8.7,2 \mathrm{H}$, phenyl), 8.31 (br s, $1 \mathrm{H}, \mathrm{NH}) ;{ }^{13} \mathrm{C}$ NMR $\delta 21.8$ (tolyl $\left.\mathrm{CH}_{3}\right), 28.8$ $\left(\mathrm{C}(\mathrm{O}) \mathrm{CH}_{2}\right)$ or $\left(\mathrm{CH}_{2} \mathrm{C}(\mathrm{O}) \mathrm{OCH}_{3}\right), 29.1\left(\mathrm{C}(\mathrm{O}) \mathrm{CH}_{2}\right)$ or $\left(\mathrm{CH}_{2} \mathrm{C}(\mathrm{O}) \mathrm{OCH}_{3}\right), 52.3\left(\mathrm{OCH}_{3}\right), 125.0$, 130.1, 140.1, 142.6 (phenyl), 172.9 ( $C=\mathrm{O}$, ester), 173.2 ( $C=\mathrm{O}$, amide); HRMS calcd for $\mathrm{C}_{12} \mathrm{H}_{16} \mathrm{NO}_{4} \mathrm{~S}\left(\mathrm{M}+\mathrm{H}^{+}\right)$270.0800. Found: 270.0790. The enantiomers were separated by HPLC (Diacel OD column, 90:10 hexanes/EtOH, $0.5 \mathrm{~mL} / \mathrm{min}, 238 \mathrm{~nm} ;(R)-\mathbf{1 m}, t_{\mathrm{R}}=26.5 \mathrm{~min} ;(S)-\mathbf{1 m}$, $\left.t_{\mathrm{R}}=61.9 \mathrm{~min}\right)$. 
$\boldsymbol{N}$-Chloroacetylbenzenesulfinamide (2c). Obtained as white solid (216 mg, 56\%): mp 92-94 ${ }^{\circ} \mathrm{C} ;{ }^{1} \mathrm{H}$ NMR $\delta 4.15$ (s, 2H, C(O)CH $\left.\mathrm{C}_{2} \mathrm{Cl}\right), 7.59$ (m, 3H, phenyl), 7.75 (m, 2H, phenyl), 8.41 (br s, $1 \mathrm{H}, \mathrm{NH}) ;{ }^{13} \mathrm{C}$ NMR $\delta 42.4\left(\mathrm{C}(\mathrm{O}) \mathrm{CH}_{2}\right), 124.9,129.8,132.7,143.0$ (phenyl), $167.3(\mathrm{C}=\mathrm{O})$; HRMS-EI calcd for $\mathrm{C}_{8} \mathrm{H}_{8}{ }^{35} \mathrm{Cl} \mathrm{NO}_{2} \mathrm{~S}\left(\mathrm{M}^{+}\right)$216.9964. Found: 216.9972. The enantiomers were separated by HPLC (Diacel OD column, 90:10 hexanes/EtOH; $0.5 \mathrm{~mL} / \mathrm{min}, 238 \mathrm{~nm} ;(R)-\mathbf{2 c}, t_{\mathrm{R}}=$ $\left.21.7 \mathrm{~min} ;(S)-2 \mathrm{c}, t_{\mathrm{R}}=43.9 \mathrm{~min}\right)$.

$N$-Dihydrocinnamoylbenzenesulfinamide (2h). Obtained as white solid (185 mg, 48\%): mp 94-96 ${ }^{\circ} \mathrm{C} ;{ }^{1} \mathrm{H}$ NMR $\delta 2.68\left(\mathrm{~m}, 2 \mathrm{H}, \mathrm{C}(\mathrm{O}) \mathrm{CH}_{2}\right), 3.02\left(\mathrm{t}, J=7.8,2 \mathrm{H}, \mathrm{CH}_{2} \mathrm{Ph}, 7.18-7.31(\mathrm{~m}, 5 \mathrm{H}\right.$, phenyl), 7.49-7.57 (m, 5H, phenyl); ${ }^{13} \mathrm{C} \mathrm{NMR}\left(\mathrm{DMSO}_{6}\right) \delta 31.1\left(\mathrm{CH}_{2} \mathrm{Ph}\right), 37.7\left(\mathrm{C}(\mathrm{O}) \mathrm{CH}_{2}\right)$, 125.6, 126.7, 128.9, 129.0, 129.9, 132.1, 141.2, 144.2 (phenyl), $174.1(C=\mathrm{O})$; HRMS calcd for $\mathrm{C}_{15} \mathrm{H}_{16} \mathrm{NO}_{2} \mathrm{~S}\left(\mathrm{M}+\mathrm{H}^{+}\right)$274.0902. Found: 274.0896. The enantiomers were separated by HPLC (Diacel AD column, 90:10 hexanes/EtOH; $0.5 \mathrm{~mL} / \mathrm{min}, 238 \mathrm{~nm} ;(R)-\mathbf{2 h}, t_{\mathrm{R}}=44.9 \mathrm{~min} ;(S)-\mathbf{2 h}, t_{\mathrm{R}}$ $=22.2 \mathrm{~min})$.

$\mathrm{N}$-Chloroacetyl-p-chlorobenzenesulfinamide (3c). Obtained as white solid (87 mg, 21\%): mp 118-120 ${ }^{\circ} \mathrm{C} ;{ }^{1} \mathrm{H}$ NMR 4.16 (s, 2H, $\left.\mathrm{C}(\mathrm{O}) \mathrm{CH}_{2} \mathrm{Cl}\right), 7.57$ (d, $J=8.4,2 \mathrm{H}$, phenyl), 7.71 (d, $J=8.4,2 \mathrm{H}$, phenyl); ${ }^{13} \mathrm{C}$ NMR $\delta 42.4\left(\mathrm{C}(\mathrm{O}) \mathrm{CH}_{2} \mathrm{Cl}\right), 126.3,130.2,139.3,141,5$ (phenyl), 167.0 $(C=\mathrm{O})$; HRMS calcd for $\mathrm{C}_{8} \mathrm{H}_{7}{ }^{35} \mathrm{Cl}_{2} \mathrm{NO}_{2} \mathrm{~S}\left(\mathrm{M}^{+}\right)$250.9574. Found: 250.9577. The enantiomers were separated by HPLC (Diacel OD column, 90:10 hexanes/EtOH; 0.5 mL/min, $238 \mathrm{~nm} ;(R)$ 3c, $\left.t_{\mathrm{R}}=28.1 \mathrm{~min} ;(S)-3 \mathbf{c}, t_{\mathrm{R}}=63.7 \mathrm{~min}\right)$.

$N$-Dihydrocinnamoyl-p-chlorobenzenesulfinamide (3h). Obtained as white solid (506 mg, 58\%): $\mathrm{mp} 133-135{ }^{\circ} \mathrm{C} ;{ }^{1} \mathrm{H}$ NMR $\delta 2.69\left(\mathrm{~m}, 2 \mathrm{H}, \mathrm{C}(\mathrm{O}) \mathrm{CH}_{2}\right), 3.02\left(\mathrm{t}, J=7.2,2 \mathrm{H}, \mathrm{CH}_{2} \mathrm{Ph}\right.$ ), 7.18-7.31 (m, 7H, phenyl), 7.46 (s, 2H, phenyl); ${ }^{13} \mathrm{C}$ NMR (DMSO-d 6$) \delta 31.0\left(\mathrm{CH}_{2} \mathrm{Ph}\right), 37.7$ $\left(\mathrm{C}(\mathrm{O}) \mathrm{CH}_{2}\right), 126.8,127.6,128.9,129.0,129.9,136.9,141.2,143.2$ (phenyl) 174.1 $(C=\mathrm{O})$; HRMS 
calcd for $\mathrm{C}_{15} \mathrm{H}_{15}{ }^{35} \mathrm{ClNO}_{2} \mathrm{~S}\left(\mathrm{M}+\mathrm{H}^{+}\right)$308.0512. Found: 308.0505. The enantiomers were separated by HPLC (Diacel OD column, 90:10 hexanes/EtOH; $0.5 \mathrm{~mL} / \mathrm{min}, 238 \mathrm{~nm} ;(R)-3 \mathbf{h}, t_{\mathrm{R}}=25.1 \mathrm{~min}$; $\left.(S)-3 \mathbf{h}, t_{\mathrm{R}}=27.9 \mathrm{~min}\right)$.

N-Chloroacetyl-p-methoxybenzenesulfinamide (4c). Obtained as white solid (152 mg, 42\%): 91-93 ${ }^{\circ} \mathrm{C} ;{ }^{1} \mathrm{H}$ NMR $\delta 3.89$ (s, 3H, $\left.\mathrm{OCH}_{3}\right), 4.14$ (s, 2H, C(O)CH$\left.H_{2} \mathrm{Cl}\right), 7.06$ (d, $J=8.7,2 \mathrm{H}$, phenyl), $7.68\left(\mathrm{~d}, J=9.3,2 \mathrm{H}\right.$, phenyl), $8.28(\mathrm{~s}, 1 \mathrm{H}, \mathrm{N} H) ;{ }^{13} \mathrm{C} \mathrm{NMR} \delta 42.4\left(\mathrm{C}(\mathrm{O}) \mathrm{CH}_{2}\right), 55.9$ $\left(\mathrm{OCH}_{3}\right), 115.2,126.6,133.9,163.1$ (phenyl), $167.2\left(\mathrm{C}=\mathrm{O}\right.$; HRMS calcd for $\mathrm{C}_{9} \mathrm{H}_{11}{ }^{35} \mathrm{ClNO}_{3} \mathrm{~S}$ $\left(\mathrm{M}+\mathrm{H}^{+}\right)$248.0148. Found: 248.0142. The enantiomers were separated by HPLC (Diacel OD column, 90:10 hexanes/EtOH; $\left.0.5 \mathrm{~mL} / \mathrm{min}, 238 \mathrm{~nm} ;(R)-\mathbf{4 c}, t_{\mathrm{R}}=31.6 \mathrm{~min} ;(S)-\mathbf{4 c}, t_{\mathrm{R}}=90.3 \mathrm{~min}\right)$. $N$-Dihydrocinnamoyl-p-methoxybenzenesulfinamide (4h). Obtained as white solid (589 mg, 66\%): $\mathrm{mp} 60-62{ }^{\circ} \mathrm{C} ;{ }^{1} \mathrm{H}$ NMR $\delta 2.67$ (m, 2H, C(O)CH $\left.\mathrm{CH}_{2}\right), 3.01\left(\mathrm{t}, J=7.5,2 \mathrm{H}, \mathrm{CH} \mathrm{H}_{2} \mathrm{Ph}\right.$ ), $3.86\left(\mathrm{~s}, 3 \mathrm{H}, \mathrm{OCH}_{3}\right), 6.98(\mathrm{~d}, J=8.7,2 \mathrm{H}$, phenyl), 7.18-7.31 (m, 5H, phenyl), $7.47(\mathrm{~d}, J=9.0$, 2H, phenyl); ${ }^{13} \mathrm{C}$ NMR (DMSO-d 6$) \delta 31.1\left(\mathrm{CH}_{2} \mathrm{Ph}\right), 37.7\left(\mathrm{C}(\mathrm{O}) \mathrm{CH}_{2}\right), 56.4\left(\mathrm{OCH}_{3}\right), 115.3,126.7$, 127.3, 128.9, 129.0, 135.2, 141.3, 162.4 (phenyl), $174.0(C=\mathrm{O})$; HRMS calcd for $\mathrm{C}_{16} \mathrm{H}_{18} \mathrm{NO}_{3} \mathrm{~S}$ $\left(\mathrm{M}+\mathrm{H}^{+}\right)$304.1007. Found: 304.1014. The enantiomers were separated by HPLC (Diacel OD column, 90:10 hexanes/EtOH; $0.5 \mathrm{~mL} / \mathrm{min}, 238 \mathrm{~nm} ;(R)-\mathbf{4 h}, t_{\mathrm{R}}=40.0 \mathrm{~min} ;(S)-\mathbf{4 h}, t_{\mathrm{R}}=42.4$ $\min )$.

$N$-Chloroacetyl-2,4,6-trimethylbenzenesulfinamide (5c). Obtained as white solid (195 mg, 28\%): $\mathrm{mp} 89-91{ }^{\circ} \mathrm{C} ;{ }^{1} \mathrm{H}$ NMR $\delta 2.33$ (s, 3H, $\left.\mathrm{PhCH}_{3}\right), 2.62\left(\mathrm{~s}, 6 \mathrm{H}, 2 \times \mathrm{PhCH}_{3}\right), 4.15$ (m, 2H, $\left.\mathrm{C}(\mathrm{O}) \mathrm{CH}_{2} \mathrm{Cl}\right), 6.92$ (s, 2H, phenyl); ${ }^{13} \mathrm{C} \mathrm{NMR} \delta 19.4\left(2 \times \mathrm{PhCH}_{3}\right), 21.4\left(\mathrm{PhCH}_{3}\right), 42.6$ $\left(\mathrm{C}(\mathrm{O}) \mathrm{CH}_{2} \mathrm{Cl}\right), 131.5,135.8,138.1,143.0$ (phenyl), $166.7(C=\mathrm{O})$; HRMS calcd for $\mathrm{C}_{11} \mathrm{H}_{14}{ }^{35} \mathrm{ClNO}_{2} \mathrm{~S} 259.0433\left(\mathrm{M}^{+}\right)$. Found: 259.0430. The enantiomers were separated by HPLC 
(Diacel OD column, 90:10 hexanes/EtOH, $0.5 \mathrm{~mL} / \mathrm{min}, 238 \mathrm{~nm} ;(R)-5 \mathbf{c}, t_{\mathrm{R}}=19.3 \mathrm{~min} ;(S)-\mathbf{5 c}, t_{\mathrm{R}}$ $=21.0 \mathrm{~min})$.

$N$-Dihydrocinnamoyl-2,4,6-trimethylbenzenesulfinamide (5h). Obtained as white solid (529 mg, 36\%): mp 125-127 ${ }^{\circ} \mathrm{C}$ (lit. $\left.{ }^{1} 126-127{ }^{\circ} \mathrm{C}\right) ;{ }^{1} \mathrm{H}$ NMR $\delta 2.31$ (s, 3H, PhCH $\left.H_{3}\right), 2.50$ (s, 6H, $\left.2 \times \mathrm{PhCH}_{3}\right), 2.68\left(\mathrm{~m}, 2 \mathrm{H}, \mathrm{C}(\mathrm{O}) \mathrm{CH}_{2}\right), 2.99\left(\mathrm{t}, J=6.9,2 \mathrm{H}, \mathrm{PhCH}_{2}\right), 6.87$ (s, 2H, phenyl), 7.16-7.29 (m, 5H, phenyl), 7.62 (br s, 1H, NH); ${ }^{13} \mathrm{C}$ NMR (DMSO-d 6 ) $\delta 19.6\left(2 \times \mathrm{PhCH}_{3}\right), 21.4$ $\left(\mathrm{PhCH}_{3}\right), 31.2\left(\mathrm{CH}_{2} \mathrm{Ph}\right), 37.4\left(\mathrm{C}(\mathrm{O}) \mathrm{CH}_{2}\right), 126.7,128.9,128.9,131.1,136.2,138.2,141.4,141.6$ (phenyl), 174.1 $(C=\mathrm{O})$. The enantiomers were separated by HPLC (Diacel OD column, 90:10 hexanes/EtOH, $\left.0.5 \mathrm{~mL} / \mathrm{min}, 238 \mathrm{~nm} ;(R)-5 \mathbf{h}, t_{\mathrm{R}}=17.6 \mathrm{~min} ;(S)-5 \mathbf{h}, t_{\mathrm{R}}=21.2 \mathrm{~min}\right)$.

$\mathrm{N}$-Chloroacetyl-1-naphthylenesulfinamide (6c). Obtained as white solid (92 mg, 22\%): mp 117-119 ${ }^{\circ} \mathrm{C} ;{ }^{1} \mathrm{H}$ NMR $\delta 4.13\left(\mathrm{~d}, J=4.8,2 \mathrm{H}, \mathrm{C}(\mathrm{O}) \mathrm{CH}_{2} \mathrm{Cl}\right), 7.61-7.72$ (m, 3H, phenyl), 7.98 (m, 2H, phenyl), 8.08 (d, $J=8.1,1 \mathrm{H}$, phenyl), 8.28 (m, 1H, phenyl); ${ }^{13} \mathrm{C}$ NMR $\delta 43.2$ $\left(\mathrm{C}(\mathrm{O}) \mathrm{CH}_{2} \mathrm{Cl}\right), 122.4,124.3,126.0,127.7,128.5,128.8,129.6,132.9,133.9,138.6$ (phenyl), 168.4 $(C=\mathrm{O})$; HRMS calcd for $\mathrm{C}_{12} \mathrm{H}_{11}{ }^{35} \mathrm{ClNO}_{2} \mathrm{~S}\left(\mathrm{M}+\mathrm{H}^{+}\right)$268.0199. Found: 268.0192. The enantiomers were separated by HPLC (Diacel OD column, 90:10 hexanes/EtOH, $0.5 \mathrm{~mL} / \mathrm{min}$, $\left.238 \mathrm{~nm} ;(R)-6 \mathbf{c}, t_{\mathrm{R}}=23.9 \mathrm{~min} ;(S)-\mathbf{6 c}, t_{\mathrm{R}}=90.2 \mathrm{~min}\right)$.

$N$-Dihydrocinnamoyl-1-naphthylenesulfinamide (6h). Obtained as white solid (302 mg, 36\%): $\mathrm{mp} 113-115{ }^{\circ} \mathrm{C} ;{ }^{1} \mathrm{H}$ NMR $\delta 2.67$ (t, $\left.J=7.5,2 \mathrm{H}, \mathrm{C}(\mathrm{O}) \mathrm{CH}_{2}\right), 2.99\left(\mathrm{~m}, 2 \mathrm{H}, \mathrm{CH}_{2} \mathrm{Ph}\right)$, 7.12-7.28 (m, 5H, phenyl), 7.54-7.65 (m, 3H, phenyl), 7.87-8.18 (m, 4H, phenyl); ${ }^{13} \mathrm{C}$ NMR $\delta$ $31.0\left(\mathrm{CH}_{2} \mathrm{Ph}\right), 37.5\left(\mathrm{C}(\mathrm{O}) \mathrm{CH}_{2}\right), 122.4,124.2,126.0,126.7,127.5,128.4,128.9,128.9,129.6$, 132.7, 133.9, 139.1, 141.2 (phenyl), $174.0(C=\mathrm{O})$; HRMS calcd for $\mathrm{C}_{19} \mathrm{H}_{18} \mathrm{NO}_{2} \mathrm{~S}\left(\mathrm{M}+\mathrm{H}^{+}\right)$ 324.1058. Found: 324.1053. The enantiomers were separated by HPLC (Diacel OD column, 90:10 hexanes/EtOH, $\left.0.5 \mathrm{~mL} / \mathrm{min}, 238 \mathrm{~nm} ;(R)-\mathbf{6 h}, t_{\mathrm{R}}=24.2 \mathrm{~min} ;(S)-\mathbf{6 h}, t_{\mathrm{R}}=37.4 \mathrm{~min}\right)$. 
$\mathrm{N}$-Chloroacetyl-2,4,6-triisopropylbenzenesulfinamide (7c). Obtained as white solid (140 mg, 15\%): mp 119-121 ${ }^{\circ} \mathrm{C} ;{ }^{1} \mathrm{H}$ NMR $\delta 1.27\left(\mathrm{~d}, J=6.9,12 \mathrm{H}, 2 \times \mathrm{CH}\left(\mathrm{CH}_{3}\right)_{2}\right), 1.37(\mathrm{~d}, J=$ 6.9, 6H, $\left.\mathrm{CH}\left(\mathrm{CH}_{3}\right)_{2}\right), 2.92\left(\mathrm{sept}, J=6.9,1 \mathrm{H}, \mathrm{CH}\left(\mathrm{CH}_{3}\right)_{2}\right), 3.93\left(\mathrm{~m}, 2 \mathrm{H}, 2 \mathrm{x} \mathrm{CH}\left(\mathrm{CH}_{3}\right)_{2}\right), 4.18(\mathrm{~s}$, $2 \mathrm{H}, \mathrm{C}(\mathrm{O}) \mathrm{CH}_{2} \mathrm{Cl}$ ), 7.14 (s, 2H, phenyl), 8.74 (br s, $1 \mathrm{H}, \mathrm{NH}$ ); ${ }^{13} \mathrm{C}$ NMR $\left(\mathrm{DMSO}_{6}\right.$ ) $\delta$ 24.3, 24.4, 24.5, 25.4, 28.8, 34.5, 39.5 (3 x $i$ - $\mathrm{Pr}), 43.1\left(\mathrm{C}(\mathrm{O}) \mathrm{CH}_{2} \mathrm{Cl}\right), 123.5,135.2,149.6,153.3$ (phenyl); HRMS calcd for $\mathrm{C}_{17} \mathrm{H}_{27}{ }^{35} \mathrm{ClNO}_{2} \mathrm{~S}\left(\mathrm{M}+\mathrm{H}^{+}\right)$344.1451. Found: 344.1443. The enantiomers were separated by HPLC (Diacel OD column, 90:10 hexanes/EtOH, $0.5 \mathrm{~mL} / \mathrm{min}, 238 \mathrm{~nm} ;(R$ or $S$ )-7c, $t_{\mathrm{R}}=8.7 \mathrm{~min} ;(R$ or $\left.S)-7 \mathbf{c}, t_{\mathrm{R}}=9.1 \mathrm{~min}\right)$.

$\mathrm{N}$-Chloroacetyl-tert-butanesulfinamide (8c). Obtained as white solid (191 mg, 29\%): mp 56-58 ${ }^{\circ} \mathrm{C} ;{ }^{1} \mathrm{H}$ NMR (200 MHz) $\delta 1.32\left(\mathrm{~s}, 9 \mathrm{H},\left(\mathrm{CH}_{3}\right)_{3}\right), 4.15$ (m, 2H, $\left.\mathrm{CH}_{2} \mathrm{Cl}\right), 7.94$ (br s, $1 \mathrm{H}$,

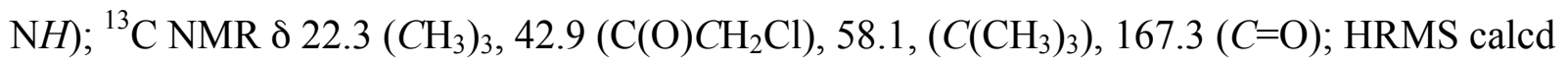
for $\mathrm{C}_{6} \mathrm{H}_{13}{ }^{35} \mathrm{ClNO}_{2} \mathrm{~S}\left(\mathrm{MH}^{+}\right)$198.0355. Found: 198.0360. The enantiomers were separated by HPLC (Diacel OD column, 90:10 hexanes/EtOH, $0.5 \mathrm{~mL} / \mathrm{min}, 222 \mathrm{~nm} ;(R$ or $S)-8 \mathbf{c}, t_{\mathrm{R}}=13.6$ $\min ;(R$ or $\left.S)-8 \mathbf{8 c}, t_{\mathrm{R}}=16.9 \mathrm{~min}\right)$.

$N$-Dihydrocinnamoyl-tert-butanesulfinamide (8h). Obtained as white solid (450 $\mathrm{mg}$, 71\%): mp 63-65 ${ }^{\circ} \mathrm{C} ;{ }^{1} \mathrm{H}$ NMR $(200 \mathrm{MHz}) \delta 1.17\left(\mathrm{~s}, 9 \mathrm{H},\left(\mathrm{CH}_{3}\right)_{3}\right), 2.72\left(\mathrm{~m}, 2 \mathrm{H}, \mathrm{C}(\mathrm{O}) \mathrm{CH} \mathrm{H}_{2}\right), 2.99$ (t, $J=7.4,2 \mathrm{H}, \mathrm{C}(\mathrm{O}) \mathrm{Ph}$ ), 7.22-7.28 (m, 5H, phenyl), 7.62 (br s, $1 \mathrm{H}, \mathrm{N} H) ;{ }^{13} \mathrm{C}$ NMR $\delta 22.3$

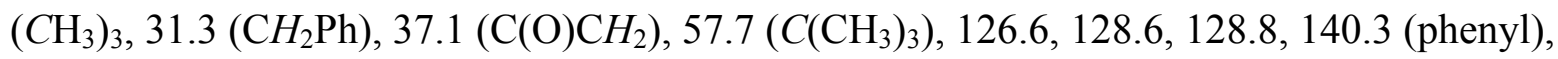
173.6 $(C=\mathrm{O})$. The enantiomers were separated by HPLC (Diacel OD column, 90:10 hexanes/EtOH, $0.5 \mathrm{~mL} / \mathrm{min}, 222 \mathrm{~nm} ;(R$ or $S)-8 \mathbf{h}, t_{\mathrm{R}}=13.6 \mathrm{~min} ;(R$ or $\left.S)-8 \mathbf{h}, t_{\mathrm{R}}=16.9 \mathrm{~min}\right)$.

Synthesis of enantiopure sulfinamide standards. Enantiopure sulfinamides were prepared using literature procedures. ${ }^{8,9}$ These compounds of known absolute stereochemical 
configuration were used as HPLC standards to determine the enantiopreference of enzymatic resolutions. Their relevant analytical data are given below:

(S)-p-Toluenesulfinamide ((S)-1). Prepared from (1R,2S,5R)-(-)-menthyl $(S)-p$ toluenesulfinate as previously described. ${ }^{8}$ This was obtained as a white solid $(620 \mathrm{mg}, 59 \%$ overall yield): $\mathrm{mp} 111-113{ }^{\circ} \mathrm{C} ;{ }^{1} \mathrm{H}$ NMR (400 MHz) $\delta 2.42$ (s, 3H, PhCH $H_{3}, 4.35$ (br s, 2H, $\left.\mathrm{N} H_{2}\right), 7.30\left(\mathrm{~d}, J=8.0,2 \mathrm{H}\right.$, phenyl), $7.61(\mathrm{~d}, J=8.4,2 \mathrm{H}$, phenyl $) ;{ }^{13} \mathrm{C} \mathrm{NMR} \delta 21.8\left(\mathrm{PhCH}_{3}\right)$, 125.6, 129.8, 141.7, 143.6 (phenyl). The ee was determined to be 97\% by HPLC (Diacel OD column, 90:10 hexanes/EtOH, $\left.1.0 \mathrm{~mL} / \mathrm{min}, 238 \mathrm{~nm} ;(R)-\mathbf{1}, t_{\mathrm{R}}=8.7 \mathrm{~min} ;(S)-\mathbf{1}, t_{\mathrm{R}}=10.3 \mathrm{~min}\right)$.

(R)-Benzenesulfinamide ((R)-2). Prepared from $(1 R, 2 S)-(+)-c i s-1$-amino-2-indanol as

previously described. ${ }^{9}$ This was obtained as a white solid (180 mg, 37\% overall yield): mp 91-93 ${ }^{\circ} \mathrm{C} ;{ }^{1} \mathrm{H}$ NMR (400 MHz) $\delta 4.38$ (br s, $2 \mathrm{H}, \mathrm{NH}$ ), 7.50 (m, 3H, phenyl), 7.74 (m, 2H, phenyl); ${ }^{13} \mathrm{C}$ NMR $\delta 125.6,129.1,131.3,146.6$ (phenyl). The ee was determined to be $96 \%$ by HPLC (Diacel AD column, 90:10 hexanes/EtOH, $1.0 \mathrm{~mL} / \mathrm{min}, 238 \mathrm{~nm} ;(R)-\mathbf{2}, t_{\mathrm{R}}=20.4 \mathrm{~min} ;(S)-\mathbf{2}, t_{\mathrm{R}}=$ 23.0min).

$(\boldsymbol{R})$-p-Chlorobenzenesulfinamide $((\boldsymbol{R})-3)$. Prepared from $(1 R, 2 S)-(+)-c i s-1$-amino-2indanol as previously described. ${ }^{9}$ This was obtained as a white solid (100 $\mathrm{mg}, 16 \%$ overall yield): mp $135-137{ }^{\circ} \mathrm{C} ;{ }^{1} \mathrm{H}$ NMR (400 MHz) $\delta 4.41\left(\mathrm{~s}, 2 \mathrm{H}, \mathrm{N} H_{2}\right), 7.47$ (d, $J=8.8,2 \mathrm{H}$, phenyl), $7.66\left(\mathrm{~d}, J=8.4,2 \mathrm{H}\right.$, phenyl); ${ }^{13} \mathrm{C}$ NMR $\delta 127.3,129.3,137.7,145.0$. The ee was determined to be $95 \%$ by HPLC (Diacel OD column, 90:10 hexanes/EtOH, $1.0 \mathrm{~mL} / \mathrm{min}, 238 \mathrm{~nm} ;(R)-3, t_{\mathrm{R}}=$ $\left.22.4 \min ;(S)-3, t_{\mathrm{R}}=37.1 \mathrm{~min}\right)$.

$(\boldsymbol{R})$-p-Methoxybenzenesulfinamide $((\boldsymbol{R})-4)$. Prepared from $(1 R, 2 S)-(+)-c i s-1$-amino-2indanol as previously described. ${ }^{9}$ This was obtained as a white solid (80 $\mathrm{mg}, 14 \%$ overall yield): mp $111-113{ }^{\circ} \mathrm{C} ;{ }^{1} \mathrm{H}$ NMR (400 MHz) $\delta 3.85$ (s, 3H, $\left.-\mathrm{OCH}_{3}\right), 4.36\left(\mathrm{~s}, 2 \mathrm{H}, \mathrm{N} H_{2}\right), 6.98(\mathrm{~d}, J=7.6$, 
2H, phenyl), 7.64 (d, $J=7.6,2 \mathrm{H}$. phenyl); ${ }^{13} \mathrm{C}$ NMR $\delta 55.9,114.5,127.3,137.9,161.9$. The ee was determined to be 95\% by HPLC (Diacel OD column, 90:10 hexanes/EtOH, $1.0 \mathrm{~mL} / \mathrm{min}, 238$ $\left.\mathrm{nm} ;(R)-4, t_{\mathrm{R}}=29.4 \mathrm{~min} ;(S)-4, t_{\mathrm{R}}=43.9 \mathrm{~min}\right)$.

$(\boldsymbol{R})-\mathbf{2 , 4 , 6}$-Trimethylbenzenesulfinamide ((R)-5). Prepared from $(1 R, 2 S)-(-)$-cis-1amino-2-indanol as previously described. ${ }^{9}$ This was obtained as a white solid $(20 \mathrm{mg}, 3 \%$ overall yield): $\mathrm{mp} 116-118{ }^{\circ} \mathrm{C} ;{ }^{1} \mathrm{H} \mathrm{NMR}(400 \mathrm{MHz}) \delta 2.29$ (s, 3H, $\left.\mathrm{PhCH}_{3}\right), 2.61$ (s, 6H, 2 x $\mathrm{PhCH}_{3}$ ), 4.41 (br s, 2H, $\mathrm{NH}$ ), 6.86 (s, 2H, phenyl); ${ }^{13} \mathrm{C} \mathrm{NMR} \delta 19.7\left(2 \times \mathrm{PhCH}_{3}\right), 21.4\left(\mathrm{PhCH}_{3}\right), 131.1$, 136.4, 139.0, 140.9 (phenyl). The ee was determined to be $68 \%$ by HPLC (Diacel OD column, 90:10 hexanes/EtOH, $\left.0.5 \mathrm{~mL} / \mathrm{min}, 238 \mathrm{~nm} ;(R)-5, t_{\mathrm{R}}=13.4 \mathrm{~min} ;(S)-5, t_{\mathrm{R}}=12.3 \mathrm{~min}\right)$.

(R)-1-Naphthylenesulfinamide ((R)-6). Prepared from $(1 R, 2 S)-(+)$-cis-1-amino-2indanol as previously described. ${ }^{9}$ This was obtained as a white solid (160 mg, 25\% overall yield): mp $151-153{ }^{\circ} \mathrm{C} ;{ }^{1} \mathrm{H}$ NMR (400 MHz) $\delta 4.40$ (br s, $\left.2 \mathrm{H}, \mathrm{N} H_{2}\right), 7.56-7.64$ (m, 3H, phenyl), 7.89-8.01 (m, 3H. phenyl), 8.22 (d, $J=8.0,1 \mathrm{H}$, phenyl); ${ }^{13} \mathrm{C}$ NMR (DMSO-d 6 ) $\delta 122.9,123.8$, $125.8,127.0,127.4,129.2,129.3,131.6,133.9,143.8$ (phenyl). The ee was determined to be 93\% by HPLC (Diacel OD column, 90:10 hexanes/EtOH, $1.0 \mathrm{~mL} / \mathrm{min}, 238 \mathrm{~nm} ;(R)-6, t_{\mathrm{R}}=52.2$ $\left.\min ;(S)-6, t_{\mathrm{R}}=49.9 \mathrm{~min}\right)$.

Cultivation and Purification of Subtilisin E. Protease deficient B. subtilis DB104 was transformed with vector pBE3, as previously described. ${ }^{10,11}$ Transformed cells were grown in $2 \mathrm{XSG}^{11}$ media $(500 \mathrm{~mL})$ with shaking for $10 \mathrm{~h}$ at $37^{\circ} \mathrm{C}$. This culture was used to inoculate $14 \mathrm{~L}$ of $2 \mathrm{XSG}^{11}$ media in a $20 \mathrm{~L}$ fermentor. After 42 hours $\left(\mathrm{OD}_{600}=9.1\right)$, the culture was cooled and centrifuged. The cell pellet was discarded and the supernatant was concentrated using a $0.45 \mu \mathrm{m}$ cartridge (8,000 MW cutoff) equipped with a $1.2 \mu \mathrm{m}$ prefilter. The concentrate was brought to $70 \%$ saturation with $\mathrm{NH}_{4} \mathrm{SO}_{4}(472 \mathrm{~g} / \mathrm{L})$, stirred overnight and then centrifuged at 8,000 rpm for 
$1.5 \mathrm{~h}$. The precipitate was resuspended and dialyzed for $48 \mathrm{~h}$ against $8 \mathrm{~L}$ of $10 \mathrm{mM}$ HEPES (pH 7.5, $1 \mathrm{mM} \mathrm{CaCl} 2$ ). The sample was passed through a bed of DE-52 anion exchange cellulose with vacuum. The clarified solution was then concentrated by passage through an 8,000 MW ultra filtration cartridge. The retentate was brought to $1.8 \mathrm{M} \mathrm{NH}_{4} \mathrm{SO}_{4}$, centrifuged and the supernatant was passed through a $0.45 \mu \mathrm{m}$ filter.

Subtilisin E was purified on a BioCad purification system (Applied Biosystems, Foster, USA) using a Poros $20 \mathrm{HP} 2(10 \times 100)$ column. ${ }^{12}$ The sample was loaded and washed with $1.8 \mathrm{M}$ $\mathrm{NH}_{4} \mathrm{SO}_{4}$ in $20 \mathrm{mM}$ HEPES (pH 7.0) and then eluted with a linear gradient of $1.8 \mathrm{M}$ to $0 \mathrm{M}$ $\mathrm{NH}_{4} \mathrm{SO}_{3}$ in $20 \mathrm{mM}$ HEPES ( $\mathrm{pH} 7.0$ ). The enzyme activity was monitored by adding $90 \mu \mathrm{L}$ of assay solution [0.2 mM succinyl-AAPF-p-nitroanilide (suc-AAPF-pNA) / 100 mM Tris pH 8.0 / $10 \mathrm{mM} \mathrm{CaCl}_{2}$ ] to $10 \mu \mathrm{L}$ of eluent and following the reaction at $410 \mathrm{~nm}$ at $37^{\circ} \mathrm{C}$ for $15 \mathrm{~min}$. The specific activity toward suc-AAPF-pNA was $21 \mathrm{U} / \mathrm{mg}$ (lit. ${ }^{10} 17.2 \mathrm{U} / \mathrm{mg}$ ). Fractions containing protein were concentrated by passage through an 8,000 MW cutoff ultrafiltration cartridge and diafiltered in $10 \mathrm{mM}$ HEPES ( $\left.\mathrm{pH} 7.5,1 \mathrm{mM} \mathrm{CaCl}_{2}\right)$. The final retentate was frozen and lyophilized to give ca. $300 \mathrm{mg}$ of subtilisin E.

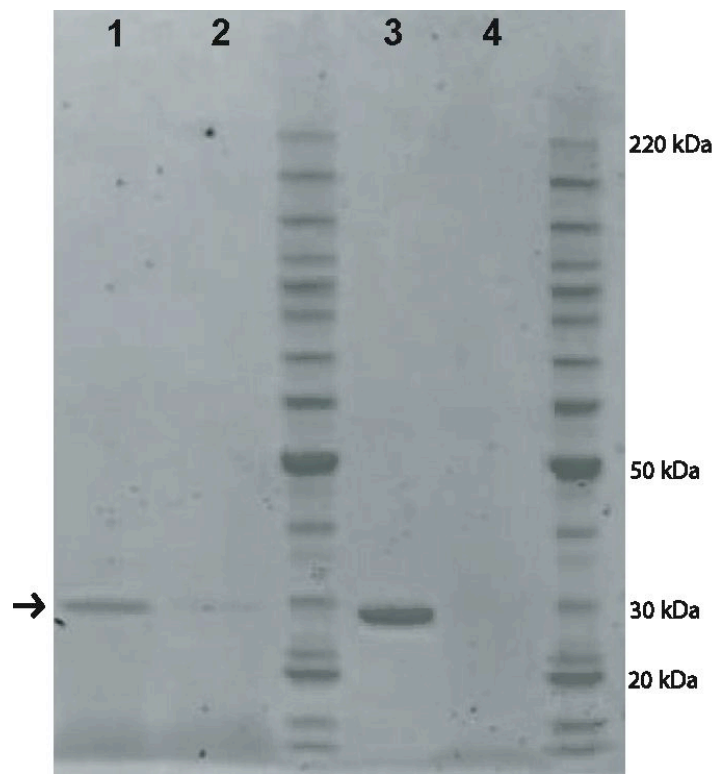


Figure S1. SDS-polyacrylamide gel electrophoresis of subtilisin E from $B$. subtilis DB104 carrying pBE3. The gel was stained by Coomassie Blue. To prevent autolysis, subtilisin E was treated with PMSF (phenylmethylsulfonylfluoride) before denaturation. PMSF (phenylmethylsulfonylfluoride) inhibited subtilisin E prepared from culture medium of $B$. subtilis DB104 carrying pBE3 is shown in lane 1. Subtilisin E prepared from culture medium of B. subtilis DB104 carrying pBE3 is shown in lane 2. Purified PMSF-inhibited subtilisin E is shown in lane 3. Purified subtilisin $\mathrm{E}$ is shown in lane 4.

Table S1. Enantioselectivity of Bacillus subtilis var. biotecus A with 2c-5c

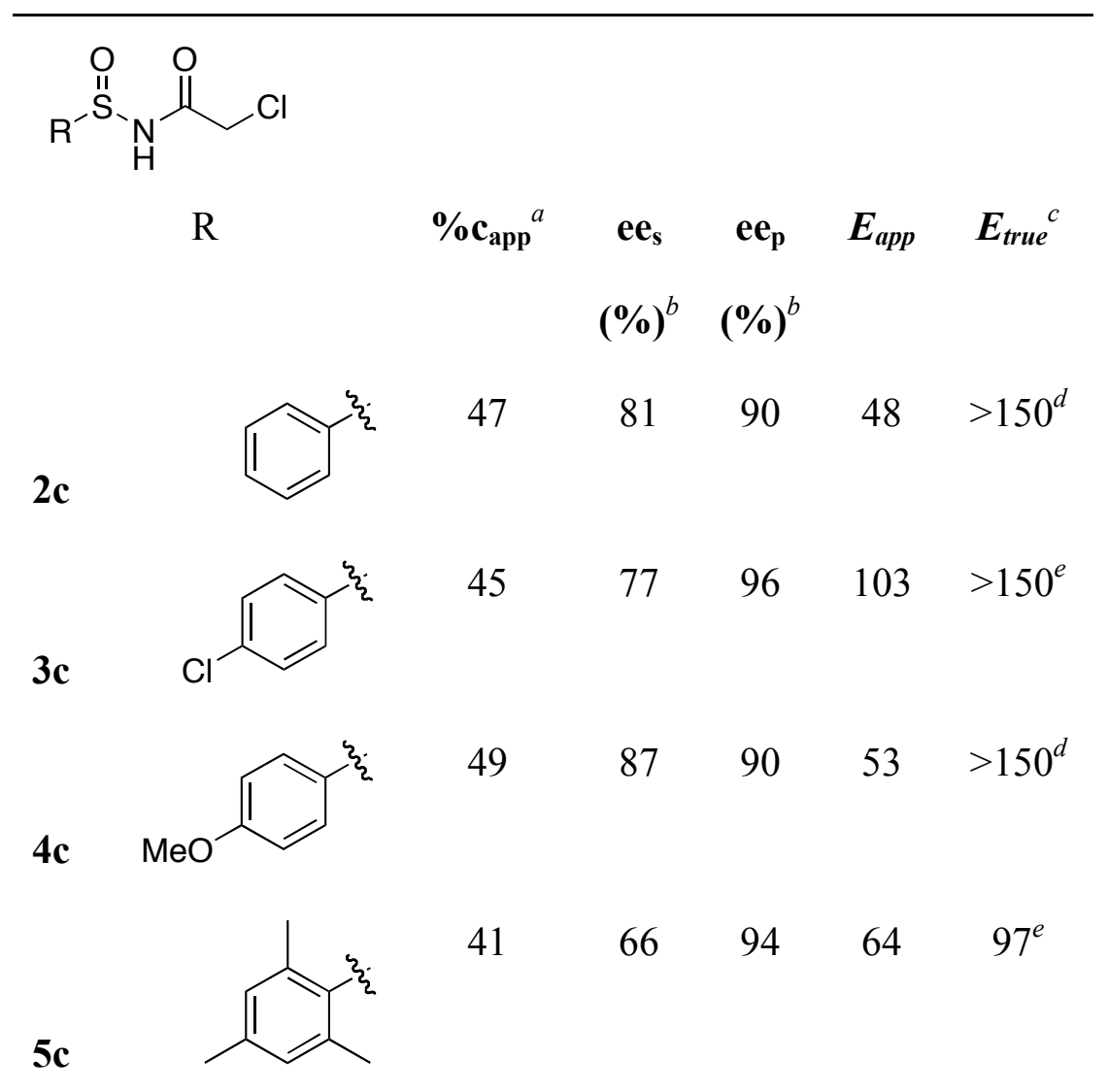

${ }^{a_{0}} \%$ Conversion: amount of sulfinamide formed in 6 h. ${ }^{b_{\%}} \%$ Enantiomeric excess. Enantiomeric excess of substrate and product were determined by HPLC analysis on Daicel Chiralcel OD or 
$\mathrm{AD}$ columns at $238 \mathrm{~nm}$ or $222 \mathrm{~nm}$. ${ }^{e}$ Enantiomeric Ratio: the enantiomeric ratio $E$ measures the relative rate of hydrolysis of the fast enantiomer as compared to the slow enantiomer as defined by Sih (Chen, C.S.; Fujimoto, Y.; Girdaukas, G.; Sih, C.J. J. Am. Chem. Soc. 1982, 104, 72947299). ${ }^{d}$ Corrected for ca. $4 \%$ chemical hydrolysis. ${ }^{e}$ Corrected for ca. $1 \%$ chemical hydrolysis.

\section{Molecular Modeling Details for $(R)-1 \mathrm{~h}$ and $(S)-1 \mathrm{~h}$ tetrahedral intermediates bound}

to Subtilisin E. Modeling $\mathbf{1 h}$ with subtilisin E gave one productive conformation for each enantiomer. The two other plausible conformations encountered severe steric clash with the protein.

Productive Conformer of $(R)-\mathbf{1 h}$. The productive complex of $(R)-\mathbf{1 h}$ had its $p$-tolyl group in the $\mathrm{S}_{1}{ }^{\prime}$ pocket and sulfoxide oxygen exposed to solvent (water). All hydrogen bond angles were $>120^{\circ}$ and all five hydrogen bond lengths were $<3.1 \AA$. The $p$-tolyl group appears to just fit in the $\mathrm{S}_{1}{ }^{\prime}$ pocket. Met222 in the bottom of the $\mathrm{S}_{1}{ }^{\prime}$ pocket $\left(\mathrm{C}_{\text {ortho }}-\mathrm{C}_{\varepsilon} \text { distance }=3.74 \AA\right)^{13}$, Tyr217 at the back of the $\mathrm{S}_{1}{ }^{\prime}$ pocket $\left(\mathrm{C}_{\text {para }}-\mathrm{C}_{\text {meta(Tyr217) }}\right.$ distance $=3.93 \AA, \mathrm{C}_{\text {meta }}-\mathrm{C}_{\text {para(Tyr217) }}$ distance $=3.94 \AA, p-\mathrm{CH}_{3}-\mathrm{C}_{\mathrm{meta}(\mathrm{Tyr} 217)}$ distance $=3.64 \AA$ and $p-\mathrm{CH}_{3}-\mathrm{C}_{\mathrm{para}(\mathrm{Tyr} 217)}$ distance $=3.93$ $\AA)^{13}$ and catalytic His64 $\left(\mathrm{C}_{\text {ortho }}-\mathrm{C}_{\delta 2} \text { distance }=3.72 \AA \text { and } \mathrm{C}_{\text {meta }}-\mathrm{C}_{\delta 2} \text { distance }=3.83 \AA\right)^{13}$ bumped the $p$-tolyl group. This tight fit suggests a favorable hydrophobic interaction between the p-tolyl group and the $\mathrm{S}_{1}{ }^{\prime}$ residues.

Non-productive Conformer of $(R)$-1h. The $p$-tolyl group of non-productive $(R)-\mathbf{1 h}$ encounters steric clash with Gly $219\left(\mathrm{C}_{\text {ortho }}-\mathrm{C}_{\alpha} \text { distance }=3.43 \AA\right)^{13}$ and catalytic Asn $155\left(\mathrm{C}_{\mathrm{ipso}}\right.$ - $\mathrm{N}_{\delta 2}$ distance $=3.41 \AA, \mathrm{C}_{\text {ortho }}-\mathrm{N}_{\delta 2}$ distance $=3.10 \AA, \mathrm{C}_{\text {meta }}-\mathrm{N}_{\delta 2}$ distance $\left.=3.37 \AA\right)^{13}$. This steric clash results in the sulfoxide oxygen being forced out of the $\mathrm{S}_{1}{ }^{\prime}$ leaving-group pocket. 
Productive Conformer of $(S)-\mathbf{1 h}$. The productive complex of $(S)$-1h had its sulfoxide oxygen in the $\mathrm{S}_{1}{ }^{\prime}$ pocket and $p$-tolyl group exposed to solvent water. All hydrogen bond angles were $>120^{\circ}$ and all five hydrogen bond lengths were $<3.1 \AA$. The sulfoxide oxygen fits well in the $\mathrm{S}_{1}{ }^{\prime}$ pocket $\left(\mathrm{O}_{\mathrm{s}}-\mathrm{C}_{\varepsilon}(\mathrm{Met} 222)\right.$ distance $=5.64 \AA$ and $\mathrm{O}_{\mathrm{s}}-\mathrm{C}_{\delta 2}(\text { His64) distance }=3.89 \AA)^{13}$ and the protein does not hinder the $p$-tolyl group. Unlike the favored enantiomer, the smaller oxygen does not make steric contact with $\mathrm{S}_{1}{ }^{\prime}$ residues. Although the slow-reacting $(S)$-enantiomer avoids steric hindrances, it also lacks favorable hydrophobic interactions between the $p$-tolyl group and the $\mathrm{S}_{1}{ }^{\prime}$ residues.

Non-productive Conformer of $(S)$-1h The tolyl group of non-productive $(S)$-1h encounters steric clash with catalytic His $64\left(\mathrm{C}_{\text {ortho }}-\mathrm{C}_{\delta 2}\right.$ distance $=3.58 \AA, \mathrm{C}_{\text {meta }}-\mathrm{C}_{\delta 2}$ distance $=$ $3.62 \AA)^{13}$. This steric clash results in the $p$-tolyl group being forced out of the $\mathrm{S}_{1}{ }^{\prime}$ leaving-group pocket.

\section{Molecular Modeling Force Field (AMBER) Parameters for the Sulfinamide Group.}

(1) Atom labels: sulfur, SO; oxygen, OX. (2) Bond parameters: SO-OX, bond length = $1.48 \AA$;

$K_{r}=680 \mathrm{kcal} / \AA$; SO-NT, bond length $=1.71 \AA K_{r}=230 \mathrm{kcal} / \AA$; SO-CA, bond length $=1.78 \AA$, $K_{r}=222 \mathrm{kcal} / \AA$ A. (3) Angle parameters: SO-NT-H, $K_{\theta}=35 \mathrm{kcal} / \mathrm{rad}^{2}, \theta_{e q}=108.9^{\circ}$; SO-CA-CA, $K_{\theta}=100 \mathrm{kcal} / \mathrm{rad}^{2}, \theta_{e q}=118.8^{\circ} ; \mathrm{OX}-\mathrm{SO}-\mathrm{CA}, K_{\theta}=74 \mathrm{kcal} / \mathrm{rad}^{2}, \theta_{e q}=107.6^{\circ} ; \mathrm{NT}-\mathrm{SO}-\mathrm{OX}, K_{\theta}=$ $100 \mathrm{kcal} / \mathrm{rad}^{2}, \theta_{e q}=112.2^{\circ} ;$ NT-SO-CA $K_{\theta}=100 \mathrm{kcal} / \mathrm{rad}^{2}, \theta_{e q}=97.1^{\circ}$. (4) Dihedral angles parameters: X-NT-SO-X, $V_{n}=5.0 \mathrm{kcal} / \mathrm{rad}^{2}, \gamma=0^{\circ}, n=3$; NT-SO-CA-CA, $V_{n}=0.0 \mathrm{kcal} / \mathrm{rad}^{2}, \gamma$ $=0^{\circ}, n=2 ; \mathrm{OX}-\mathrm{SO}-\mathrm{CA}-\mathrm{CA}, V_{n}=0.0 \mathrm{kcal} / \mathrm{rad}^{2}, \gamma=0^{\circ}, n=2 .(5)$ Nonbonded parameters: SO, $R^{*}$ $=2.00 \AA, \varepsilon=0.20 \mathrm{kcal} / \mathrm{mol} ; \mathrm{OX}, R^{*}=1.60 \AA, \varepsilon=0.20 \mathrm{kcal} / \mathrm{mol}$. 
Figure S2. Catalytically productive tetrahedral intermediates for the subtilisin E catalyzed hydrolysis of (S)-7c (I) and (S)-7c (II) as identified by molecular modeling. The important active site and substrate atoms (sticks) are colored as follows: grey (carbon), red (oxygen), blue (nitrogen), orange (sulfur) and pink (chlorine). Surrounding atoms (space fill) of subtilisin are shown in blue. For clarity, all hydrogen atoms and water molecules are hidden. Both I and II maintain all catalytically essential hydrogen bonds and the chloroacetyl group binds in the $\mathrm{S}_{1}$ pocket. The triisopropyl benzene group (Large) or sulfoxide oxygen (Medium) was bound in the leaving-group $\mathrm{S}_{1}{ }^{\prime}$ pocket. However, both groups were forced out of the $\mathrm{S}_{1}{ }^{\prime}$ pocket because of steric hindrance between the triisoproyl group and active site residues. The productive orientation of slow-reacting $(S)$-7c differs from $(S)$-1h because of steric clash between the triisopropyl group and the oxyanion residue Asn 155 when the sulfoxide oxygen is bound in the $\mathrm{S}_{1}{ }^{\prime}$ pocket. This forces the substrate to rotate about the $\mathrm{S}-\mathrm{N}$ bond, which places the triisopropyl group above the $\mathrm{S}_{1}{ }^{\prime}$ pocket.-This conformation is similar to the productive orientation of fastreacting $(R)$-7c. Since the aryl group of both $(R)-7 \mathbf{c}$ and $(S)-7 \mathbf{c}$ bind above the $\mathrm{S}_{1}{ }^{\prime}$ pocket, there is little difference in their binding conformations and the enantioselectivity is low $(E=1.2)$. 


\section{I}

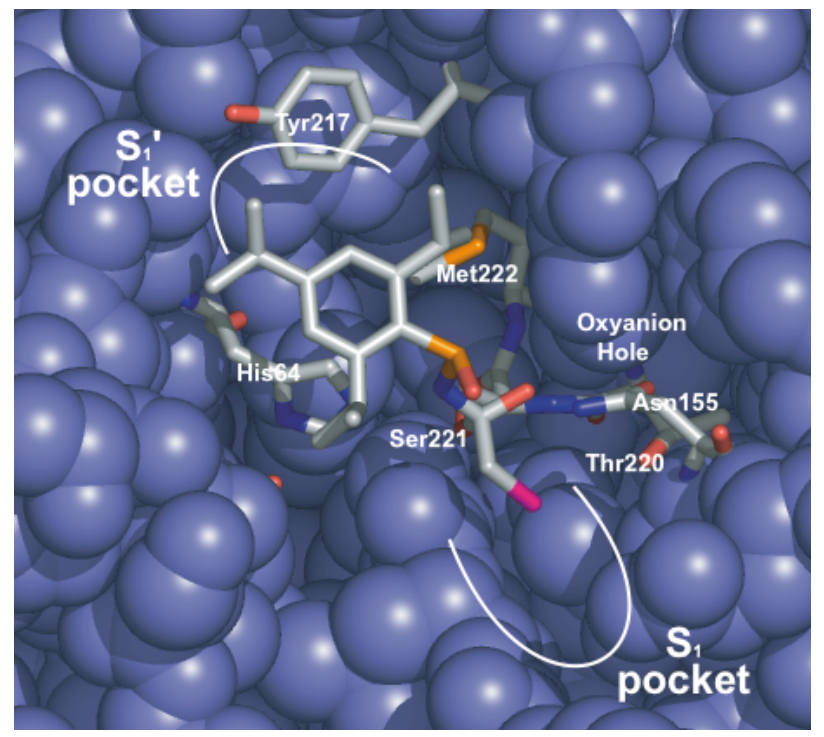

II

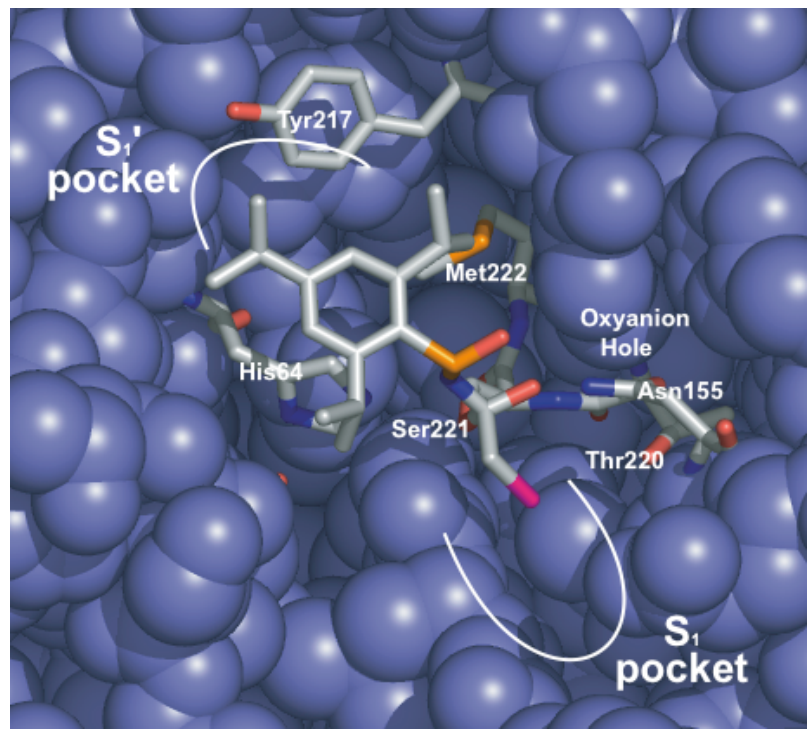

\section{References}

1. Backes, B. J.; Dragoli, D. R.; Ellman, J. A. J. Org. Chem. 1999, 64, 5472-5478.

2. Dahn, H.; Van Toan V.; Ung Truong, M. -N. Magn. Reson. Chem. 1991, 29, 897-903. 
3.We are unable to account for the discrepancy with the previously reported mp value. However, the ${ }^{1} \mathrm{H}$ and ${ }^{13} \mathrm{C}$ NMR spectra correspond to the proposed structure of 7 and agree with the previously reported data. ${ }^{1}$

4. Netscher, T.; Prinzbach, H. Synthesis 1987, 683-686.

5. Gontcharov, A.V.; Liu, H.; Sharpless, K.B. Org. Lett. 1999, 1, 783-786.

6. Cogan, D.A.; Liu, G.; Kim, K.; Backes, B.J.; Ellman, J.A. J. Am. Chem. Soc. 1998, 120, 80118019.

7. Chen, F.M.F.; Kuroda, K.; Benoiton, N.L. Synthesis 1978, 928-929.

8. Davis, F. A.; Xhang, Y.; Andemichael, Y.; Fang, T.; Fanelli, D. L.; Zhang, H. J. Org. Chem. 1999, 64, 1403-1406.

9. Han, Z.; Krishnamurthy, D.; Grover, P.; Fang, K.; Senanayake, C.H. J. Am. Chem. Soc. 2002, $124,7880-7881$.

10. Zhao, H.; Arnold, F. H. Proc. Natl. Acad. Sci. USA 1997, 94, 7997-8000.

11. Harwood, C. R.; Cutting, S. M. Molecular Biological Methods for Bacillus, John Wiley and Sons, England, 1990, pp 33-35, 391-402.

12. Cho, S.-J.; OH, S.-H.; Pridmore, R. D.; Juillerat, M. A.; Lee, C.-H. J. Agric. Food Chem. 2003, 51, 7664-7670.

13. The van der Waals distance for $\mathrm{CH}-\mathrm{C}=3.99 \AA, \mathrm{CH}-\mathrm{N}=3.84 \AA, \mathrm{CH}-\mathrm{S}=4.09 \AA$ and $\mathrm{O}-\mathrm{HC}=$ $3.81 \AA$. These were estimated from the van der Waals radii of carbon $(1.70 \AA)$, nitrogen $(1.55$ $\AA)$, sulfur $(1.80 \AA)$ or oxygen $(1.52 \AA)$ and hydrogen $(1.20 \AA)$ and the C-H bond length $(1.09 \AA)$ or O-H bond length (0.96 ̊̊) from Bondi, A. J. Phys. Chem. 1964, 68, 441-451. 